This item was submitted to Loughborough's Research Repository by the author.

Items in Figshare are protected by copyright, with all rights reserved, unless otherwise indicated.

\title{
Modelling the location and consequences of aircraft accidents
}

PLEASE CITE THE PUBLISHED VERSION

http://dx.doi.org/10.1016/j.ssci.2012.05.012

PUBLISHER

(c) Elsevier

VERSION

AM (Accepted Manuscript)

LICENCE

CC BY-NC-ND 4.0

REPOSITORY RECORD

Ayres, Manuel, Hamid Shirazi, Regis Carvalho, Jim Hall, Richard Speir, Edith Arambula, Robert David, et al.. 2019. "Modelling the Location and Consequences of Aircraft Accidents". figshare.

https://hdl.handle.net/2134/10984. 
This item was submitted to Loughborough's Institutional Repository (https://dspace.lboro.ac.uk/) by the author and is made available under the following Creative Commons Licence conditions.

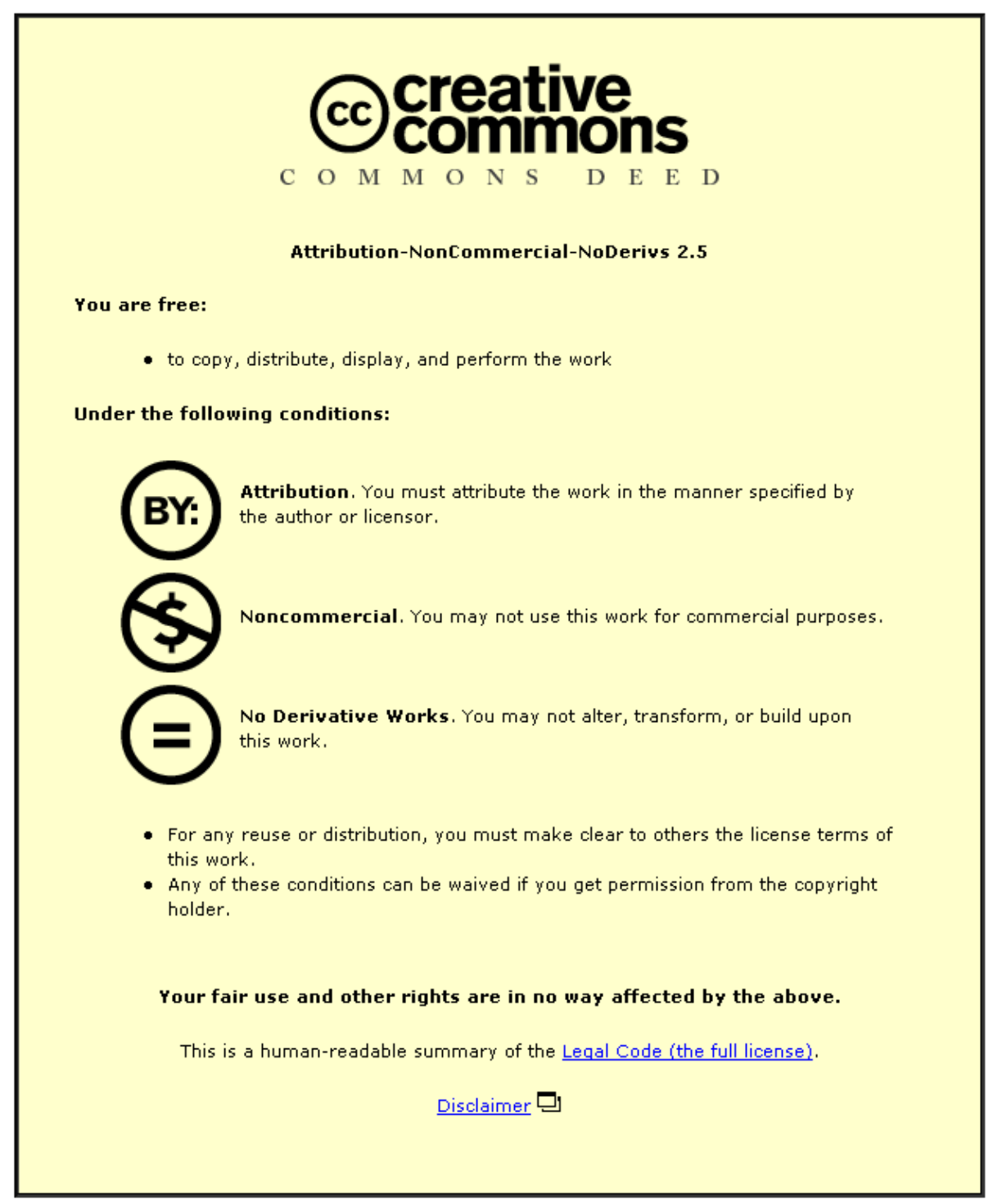

For the full text of this licence, please go to: http://creativecommons.org/licenses/by-nc-nd/2.5/ 
Modelling the Location and Consequences of Aircraft Accidents ${ }^{1}$.

Manuel Ayres $\mathrm{Jr}^{2}$., Hamid Shirazi ${ }^{*}$, Regis Carvalho*, Jim Hall, ${ }^{*}$ Richard Speir ${ }^{*}$, Edith Arambula*, Robert David ${ }^{3}$, John Gadzinski ${ }^{4}$, Robert Caves ${ }^{5}$, Derek Wong ${ }^{5}$, David Pitfield $^{5}$.

Following the completion of two projects funded by the UK EPSRC and two for the Airports Cooperative Research Program, ACRP $(2008,2011)$, this paper aims to summarise the work on the location and consequence models ${ }^{6}$. The projects overall focused on the development of an improved airport risk assessment methodology aimed at assessing risks related to aircraft accidents at and in the vicinity of airports and managing Runway Safety Areas (RSAs) as a risk mitigation measure. The improved methodology is more quantitative, risk-sensitive, flexible and transparent than traditional risk assessment approaches. As such, it contributes to the implementation of Safety Management Systems at airports, as stipulated by the International Civil Aviation Organisation. The innovative elements of this research are two-fold. First, an accident database covering undershoots, overruns, and veeroff crashes close to runways at airports has been compiled and data on incidents has been added. Second, accident frequency models have been developed, for example, identifying the contribution of influencing factors such as variations in meteorological conditions. To allow airport risk to then be calculated entails comparing these cases with those contained in a 'normal operations database' where no accidents have been recorded but where the influencing factors are also known. Subsequent models have examined the location of the accidents and their

\footnotetext{
${ }^{1}$ This paper is based on ACRP(2011)

${ }^{2}$ Airport Safety Management (ASM) Consultants, FLA., http://www.asmcons.com/

* Applied Research Associates, Inc.,MD., http://www.ara.com/Projects/p_runaway_safety.htm

${ }^{3}$ Robert E.David \& Associates, Inc.,VA., http://www.robertedavid.com/Home.html

${ }^{4}$ For Winds Consulting,VA., http://fourwinds-safety.com/

${ }^{5}$ Transport Studies Group, Loughborough University, U.K.

${ }^{6}$ The expertise for implementing these models rests with Airport Safety Management Consultants.
} 
consequences. It is this work that is the focus of this paper. Future work will focus on improving these aspects of the modelling and the consequences of crashes more than $2000 \mathrm{ft}$. but less than 10 miles from a runway end as well as impacts on third parties.

1 Introduction

Landing and takeoff overruns, landing undershoots, and landing and takeoff veeroffs account for most of the accidents that occur on or in the immediate vicinity of the runway. Accident statistics show that, from 1959 to $2009,55 \%$ of the world's jet fatal aircraft accidents occurred during landing and takeoff phases of the flight and accounted for $51 \%$ of all onboard fatalities (Boeing, 2010).

The previous research in Wong (2007), which is also reported in Wong et al (2006a, 2006b) and Wong et al (2009a, 2009b) as well as ACRP (2008), aimed to develop a risk assessment tool that could be used to evaluate alternatives for RSAs. This work was developed in ACRP (2011). Five sets of models were developed: landing overruns, landing veer-offs, landing undershoots, takeoff veer-offs, and takeoff overruns. Each set included an accident and incident frequency model and this paper adds location models and consequence models. Recommendations can follow from these models to modify the RSA. 
Accident and incident data were collected from a variety of sources and these are listed below:

- $\quad$ FAA Accident/Incident Data System (AIDS).

- $\quad$ FAA/National Aeronautics \& Space Administration (NASA) Aviation Safety - $\quad$ Reporting System (ASRS).

- $\quad$ National Transportation Safety Board (NTSB) Accident Database \& Synopses. MITRE Corporation Runway Excursion Events Database V.4 (2008). Transportation Safety Board of Canada (TSB).

- International Civil Aviation Organization (ICAO) Accident/Incident Data - $\quad$ Reporting (ADREP) system.

- $\quad$ Australian Transport Safety Bureau (ATSB).

- Bureau d'Enquêtes et d'Analyses pour la Sécurité de l'Aviation Civile (BEA). UK Air Accidents Investigation Branch (AAIB).

- New Zealand Transport Accident Investigation Commission (TAIC). Air Accident Investigation Bureau of Singapore.

- Ireland Air Accident Investigation Unit (AAIU).

- Spain Comisión de Investigación de Accidentes e Incidentes de Aviación Civil (CIAIAC).

- Indonesia National Transportation Safety Committee (NTSC). Netherlands Aviation Safety Board (NASB). 
More than 260,000 aviation accident and incident reports were screened from 11 countries to identify the cases relevant to this study. Out of those, more than 140,000 events were screened from U.S. databases.

A list of accidents and incidents containing the cases used for model development is presented in Appendix B of ACRP (2011). The list includes the accidents that occurred within $2000 \mathrm{ft}$. of the runway ends and within $1000 \mathrm{ft}$. of the runway centreline. The criteria represents the area where the overwhelming majority of runway excursions and undershoots occur, and are similar to those used in ACRP (2008) and by David (1990) for the FAA. Using such criteria, 1414 accidents and incidents were identified to provide the information used to develop the frequency and location models. Events that took place since 1980 and for which reports were available were included in the database.

\section{Preliminary Statistics}

Figure 1 presents the summary of accidents and incidents by type, and Figure 2 shows the relative percentages for each type. Landing events accounted for $83 \%$ of the events. Overruns (landing and takeoffs) accounted for $44 \%$ of accidents and incidents; veer-offs accounted for $48 \%$; and undershoots accounted for only $8 \%$ of the total number of events. 


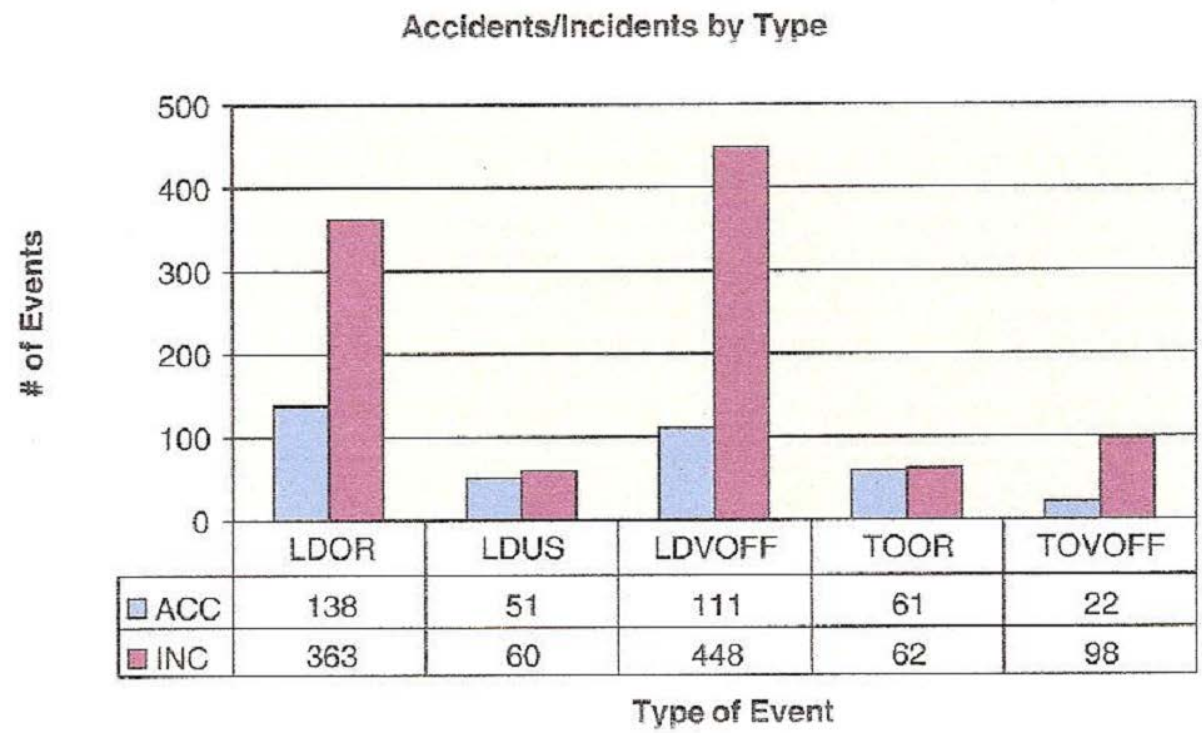

Figure 1: Summary of accidents and incident by type

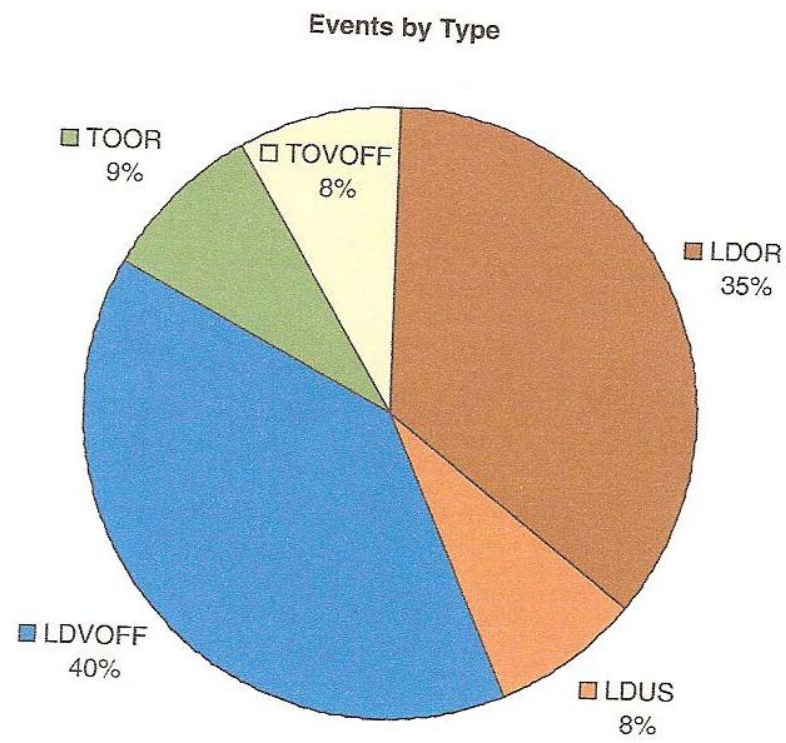

Figure 2: Percentage of accidents and incidents by type 
Figure 3 presents the number of incidents and accidents by year from 1978 to 2008 . The number of events reported in the 1970‘s was relatively low, most likely due to underreporting and lower volumes of traffic. The number of events increased slowly, and there is a sharp drop during the past 3 years. It is possible that some events are still undergoing the investigation and that reports were not available by the time data collection was completed.

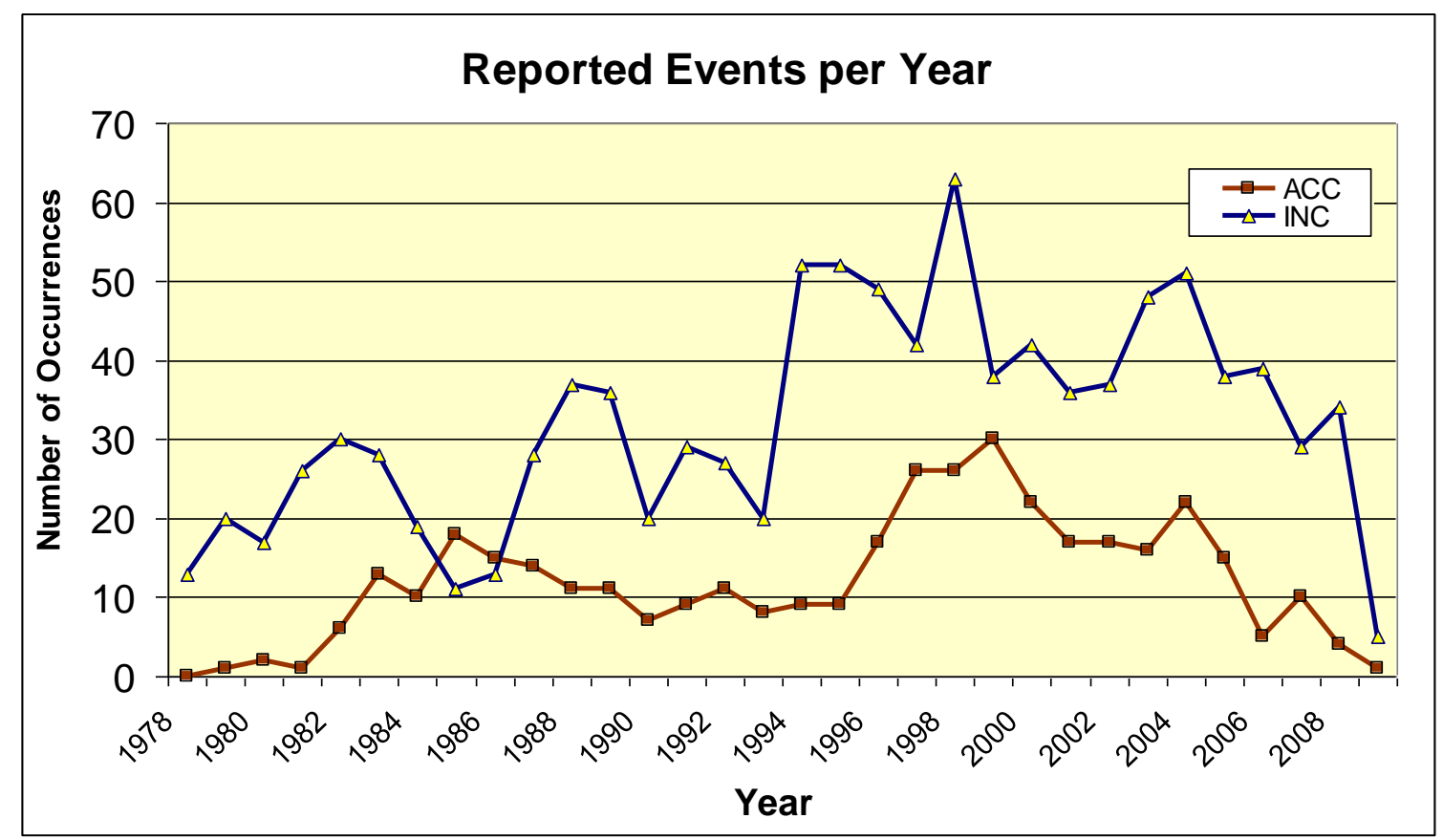

Figure 3. Number of reported accidents and incidents from 1978 to 2008

Figures 4 to 8 show the distribution of accidents and incidents according to their location. For overruns and undershoots, the locations refer to the longitudinal distance from the runway end, that is the threshold. For veer-offs, it is the lateral distance from the runway longitudinal edge. 


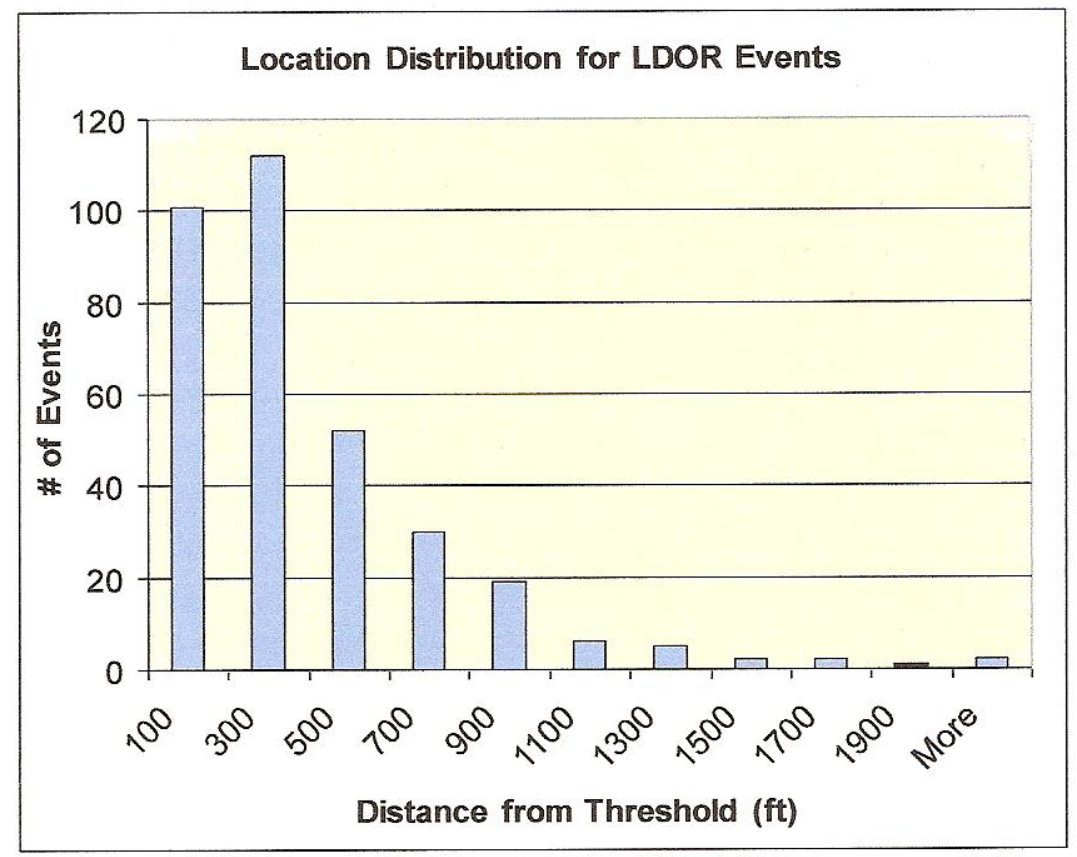

Figure 4. Location distribution for landing overruns

501 landing overrun events were identified. In approximately $95 \%$ of the events, the aircraft stopped within 1000 feet after overrunning the runway, and close to $77 \%$ stopped within 500 feet.

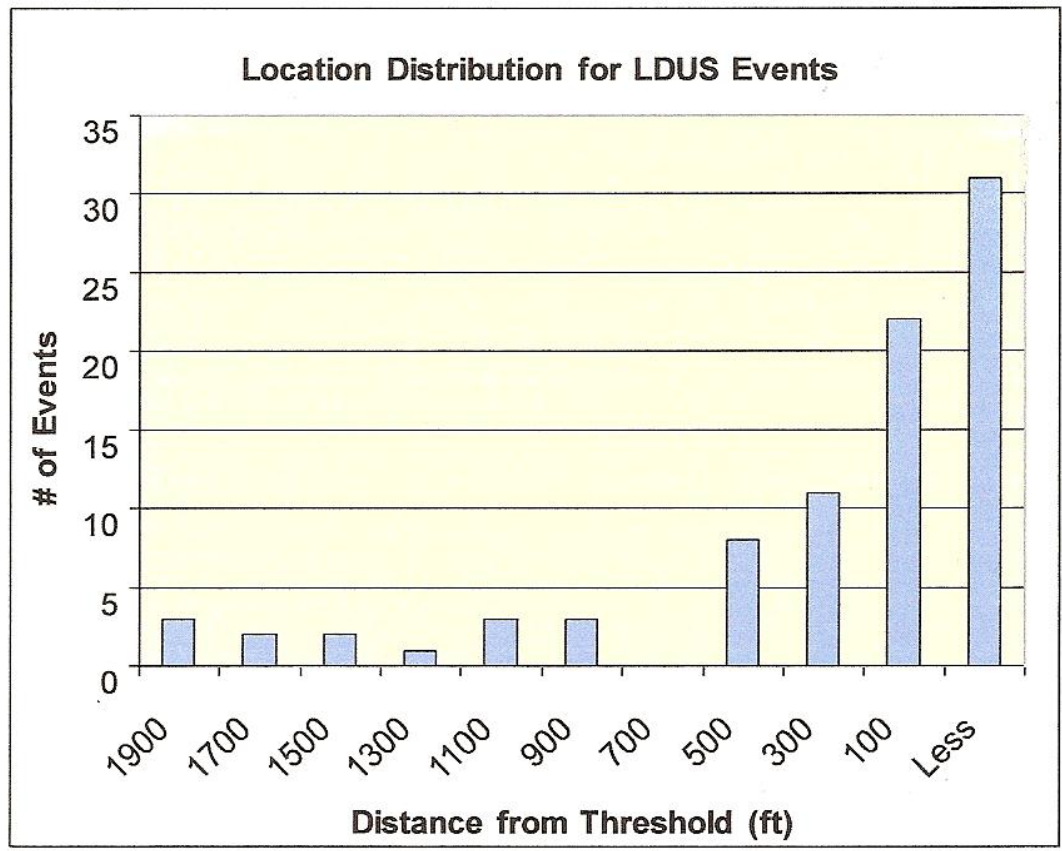

Figure 5. Location distribution for landing undershoots 
111 landing undershoot events were identified, and in approximately $94 \%$ of the cases, the aircraft touched the terrain within 1000 feet of the runway arrival end. Approximately $85 \%$ touched down within 600 feet and $80 \%$ within 500 feet.

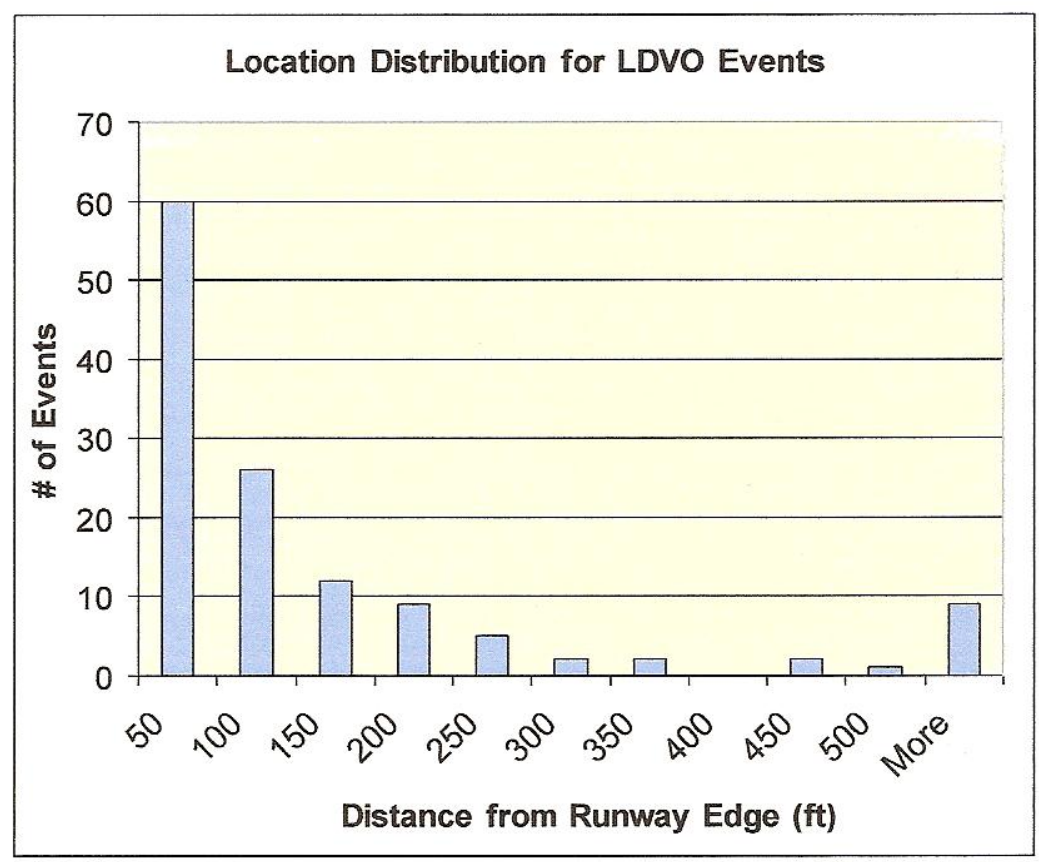

Figure 6. Location distribution for landing veer-offs

Veer-off distances were measured from the runway edge. Of the 559 cases of landing veer-off identified, in approximately $80 \%$ of the cases the fuselage of the aircraft deviated less than 175 feet from the runway edge. For $88 \%$ of the events, the aircraft was within 250 feet of the runway edge. 


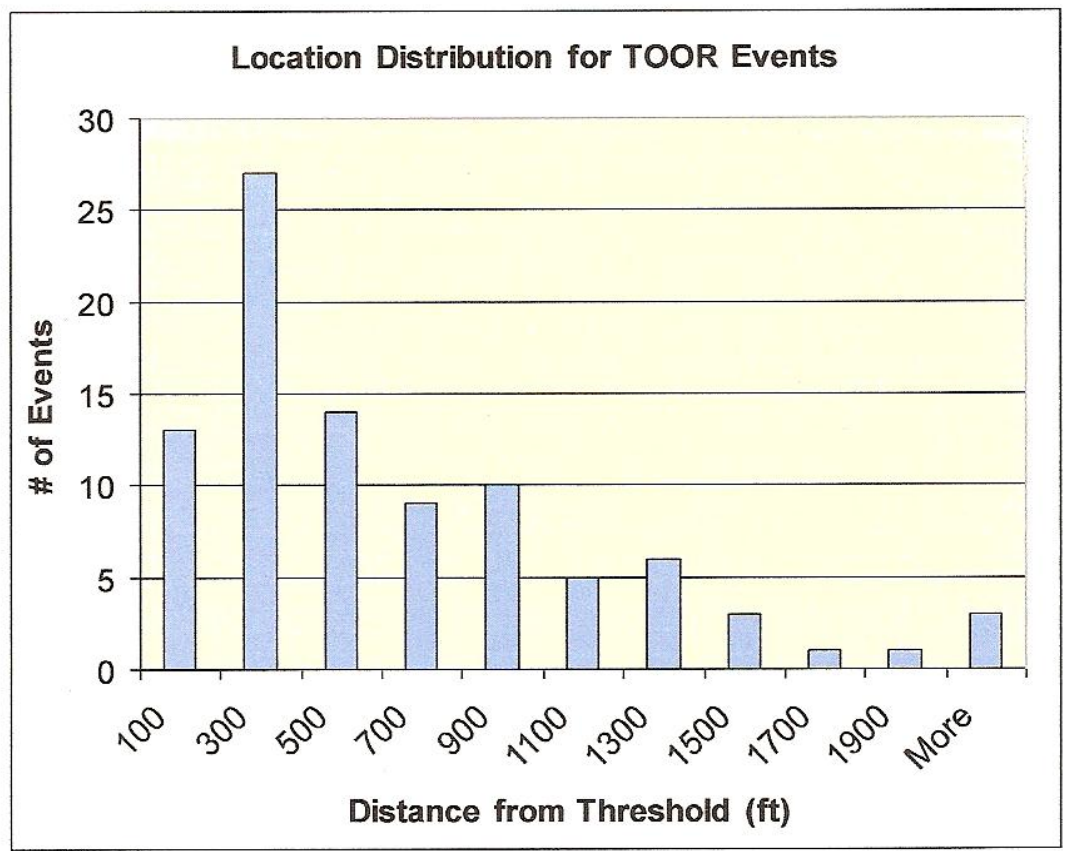

Figure 7. Location distribution for takeoff overruns

A total of 123 takeoff overrun accidents and incidents were identified. For approximately $83 \%$ of the cases, the stop location was within 1000 feet of the runway departure end, and for $56 \%$, the aircraft stopped within 500 feet

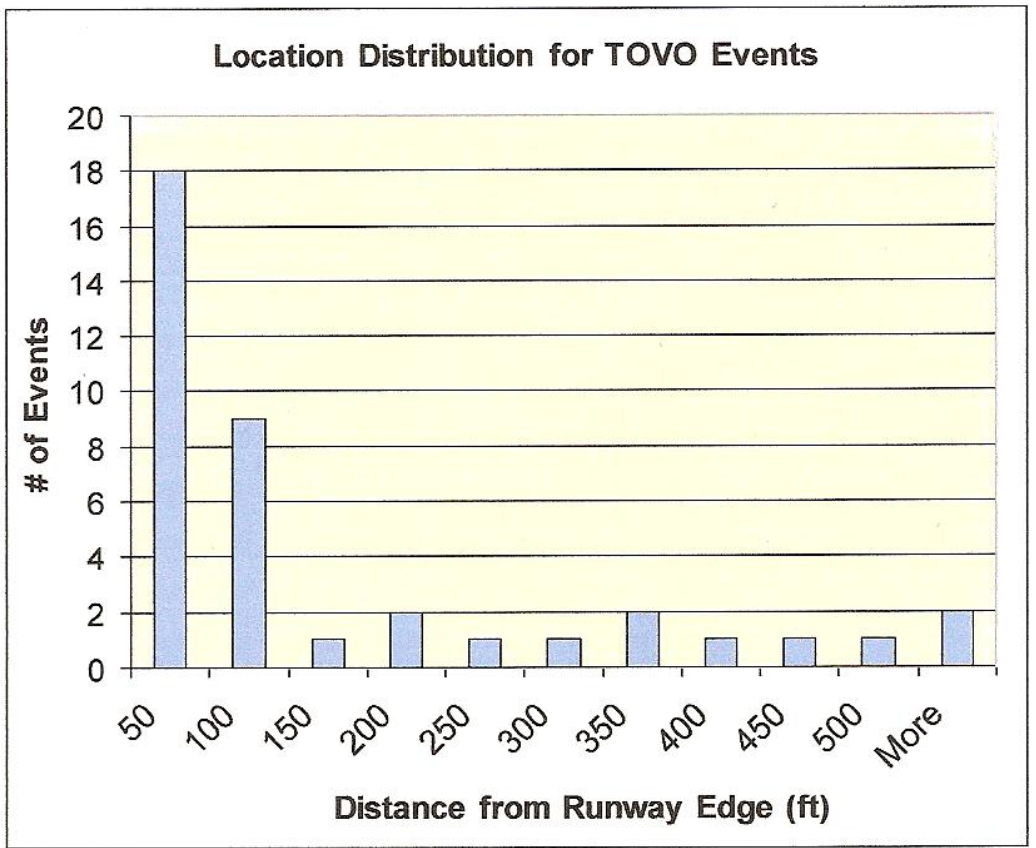

Figure 8. Location distribution for takeoff veer-offs 
Of the 120 takeoff veer-off accidents and incidents, in approximately $76 \%$ of the cases the fuselage of the aircraft deviated less than 175 feet from the runway edge. In $85 \%$ of the events, the aircraft was within 250 feet of the runway edge.

\section{$4 \quad$ Modelling Aircraft Accidents}

The first component in the modelling, the frequency model is used to estimate the probability that an event will occur given certain operational conditions. This probability does not address the likelihood that the aircraft may strike an obstacle or will stop beyond a certain distance. The model uses independent variables associated with causal and contributing factors for the incident. For example, under tailwind conditions it is more likely that an overrun will occur, and this is one of the factors used in the models for overruns. The aircraft performance is represented by the interaction between the runway distance required by the aircraft for the given conditions and the runway distance available at the airport. Although human and organisational factors are among the most important causes of aircraft accidents, it was not possible to directly incorporate these factors into the risk models. Since this model is specific for the event type, five different models are required, one for each accident type.

The second component is the location model. The analyst usually is interested in evaluating the likelihood that an aircraft will depart the runway and stop beyond the RSA or strike an obstacle. The location model is used to estimate the probability that the aircraft stops beyond a certain distance from the runway. As pointed out in ACRP (2008) and by Wong (2007), the probability of an accident is not equal for all 
locations around the airport. The probability of an accident in the proximity of the runways is higher than at larger distances from the runway. Since this model is specific for the event type, five different models are again required.

The last component is the consequence model which was first addressed by Kirkland et al (2004). This model uses the location models to assess the likelihood that an aircraft will strike an obstacle or depart the RSA and fall into a drop in the terrain or into a water body adjacent to the RSA. In addition, it takes into consideration the type of obstacle and the estimated collision speed to cause severe consequences. For example, an aircraft colliding with a brick building may result in severe consequences even at low speeds; however, the aircraft must be at a higher speed when striking a Localiser antenna mounted on a frangible structure for a similar level of severity. The collision speed is evaluated based on the location of the obstacle and the typical aircraft deceleration for the type of RSA terrain.

\section{$5 \quad$ Location Models}

The accident location models are based on historical accident data for aircraft overruns, veer-offs, and undershoots. The accident location for overruns depends on the type of terrain (paved or unpaved) and if an Engineered Materials Arrestor System (EMAS) is installed in the RSA. When EMAS is available, during landing and takeoff overruns, the aircraft will stop at shorter distances, and typical deceleration for the type of aircraft should include this factor in determining the location probability. Worldwide data on accidents and incidents were used to develop the location models. The model structure is similar to the one used by Eddowes (2001). Based 
on the accident/incident location data, five sets of complementary cumulative probability distribution (CCPD) models were developed. With CCPD‘s, the fraction of accidents involving locations exceeding a given distance from the runway end or threshold can be estimated. When the CCPD is multiplied by the frequency of accident occurrence, a complementary cumulative frequency distribution (CCFD) is obtained and is described in detail in Wong et al (2009b). The latter quantifies the overall frequency of accidents involving locations exceeding a given distance from the runway boundaries.

Figures 9 to 11 show the axis locations used to represent each type of incident. The reference location of the aircraft is its nose wheel. For overruns and undershoots, the $x-y$ origin is the centreline at the runway end. For veer-offs, the $y$-axis origin is the edge of the runway, not necessarily the edge of the paved area when the runway has shoulders.
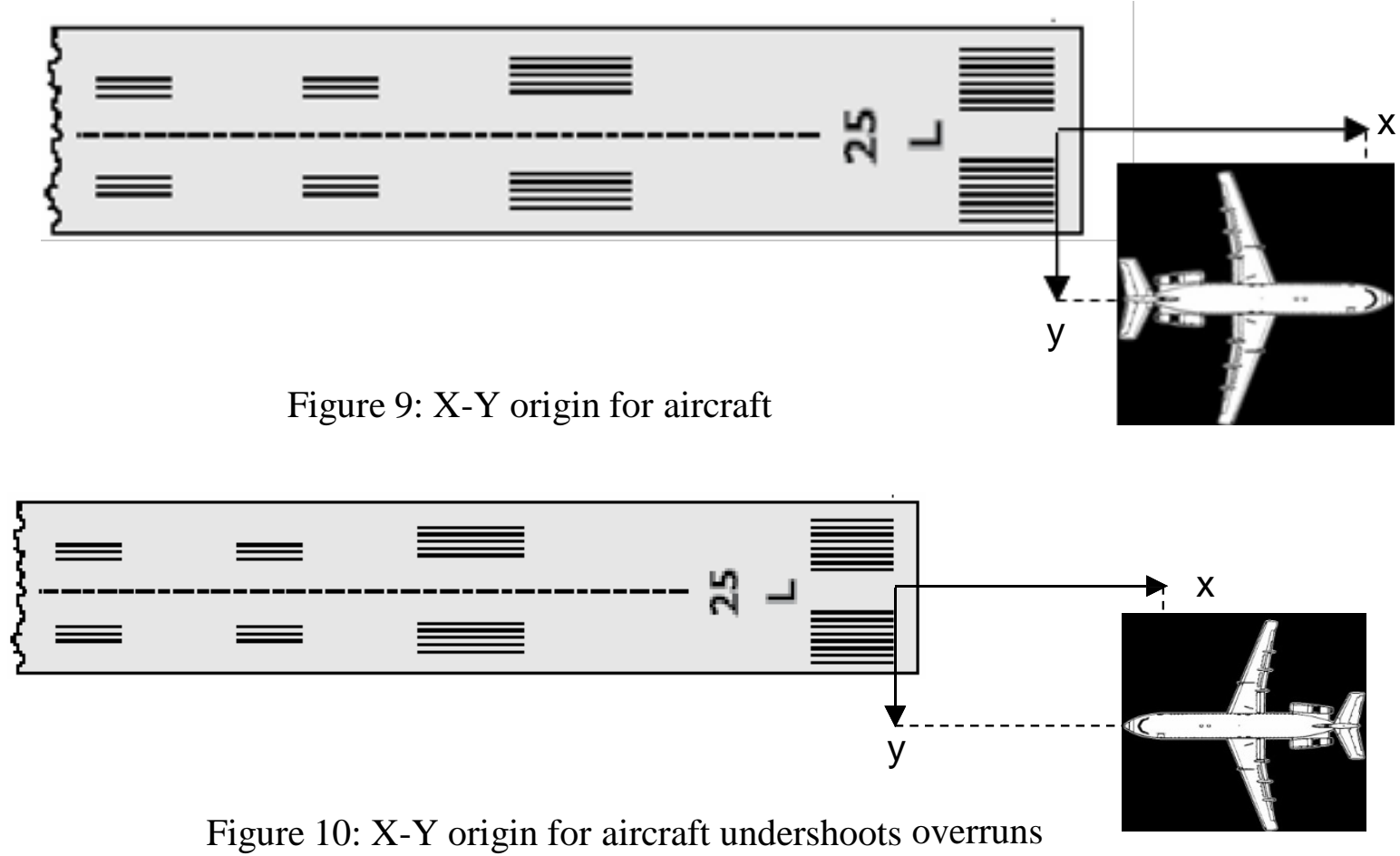


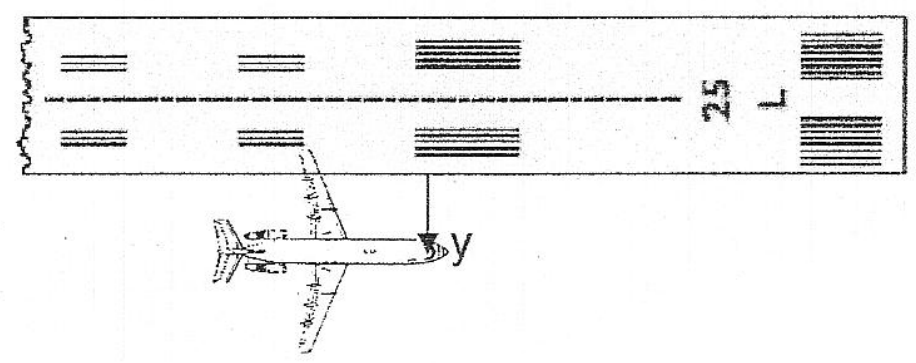

Figure 11: Y origin for aircraft veer-offs

For the longitudinal distribution, the basic model is:

$$
P\{\text { Location }>x\}=e^{-a x^{n}}
$$

Where

- $P\{$ Location $>x\}$ is the probability the overrun/undershoot distance along the runway centreline beyond the runway end is greater than $x$

- $x$ is a given location or distance beyond the runway end

- $a, n$ are regression coefficients

A typical longitudinal location distribution is presented in Figure 12.

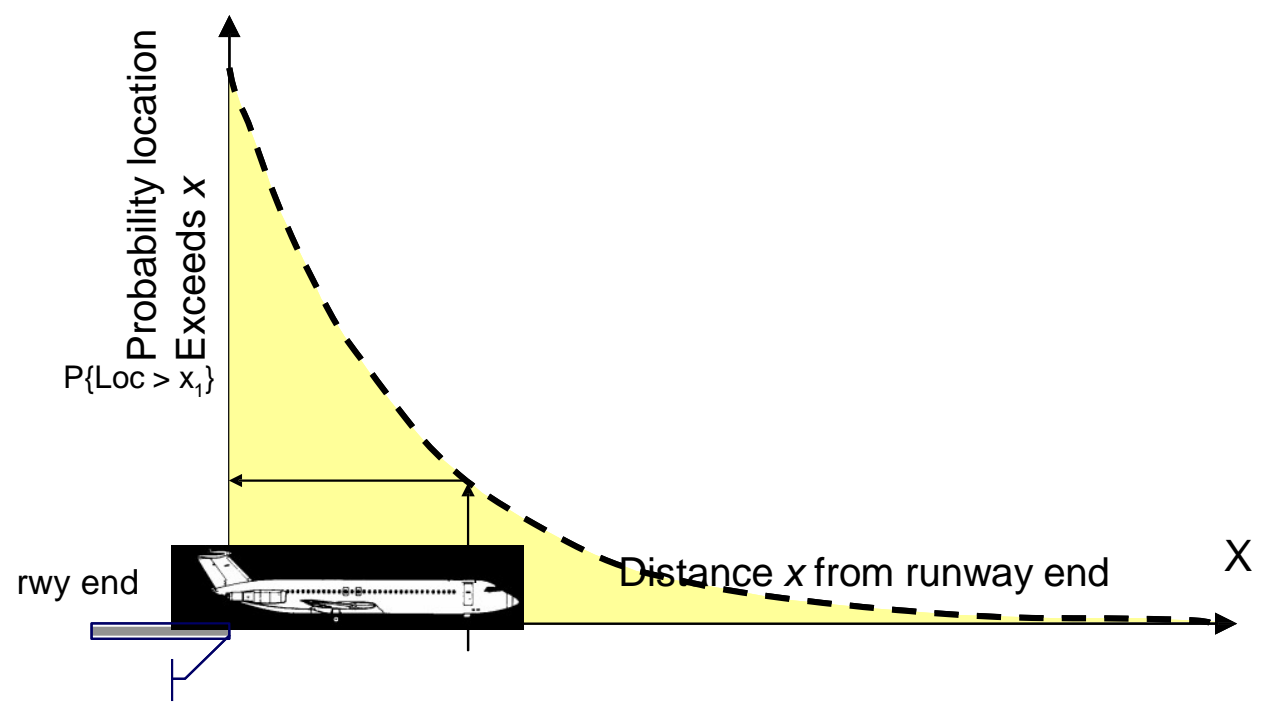

Figure 12 Typical model for aircraft overruns. 
The model for the transverse distribution can be represented by the following equation:

$$
P\{\text { Location }>y\}=e^{-b y^{m}}
$$

where

- $P\{$ Location $>y\}$ is the probability the overrun/undershoot distance from the runway border (veer-offs) or centreline (overruns and undershoots) is greater than $y$

- $y$ is a given location or distance from the extended runway centreline or runway border

- $\quad b, m$ are regression coefficients

A typical transverse location distribution is presented in Figure 13, and the model parameters are presented in Table 1

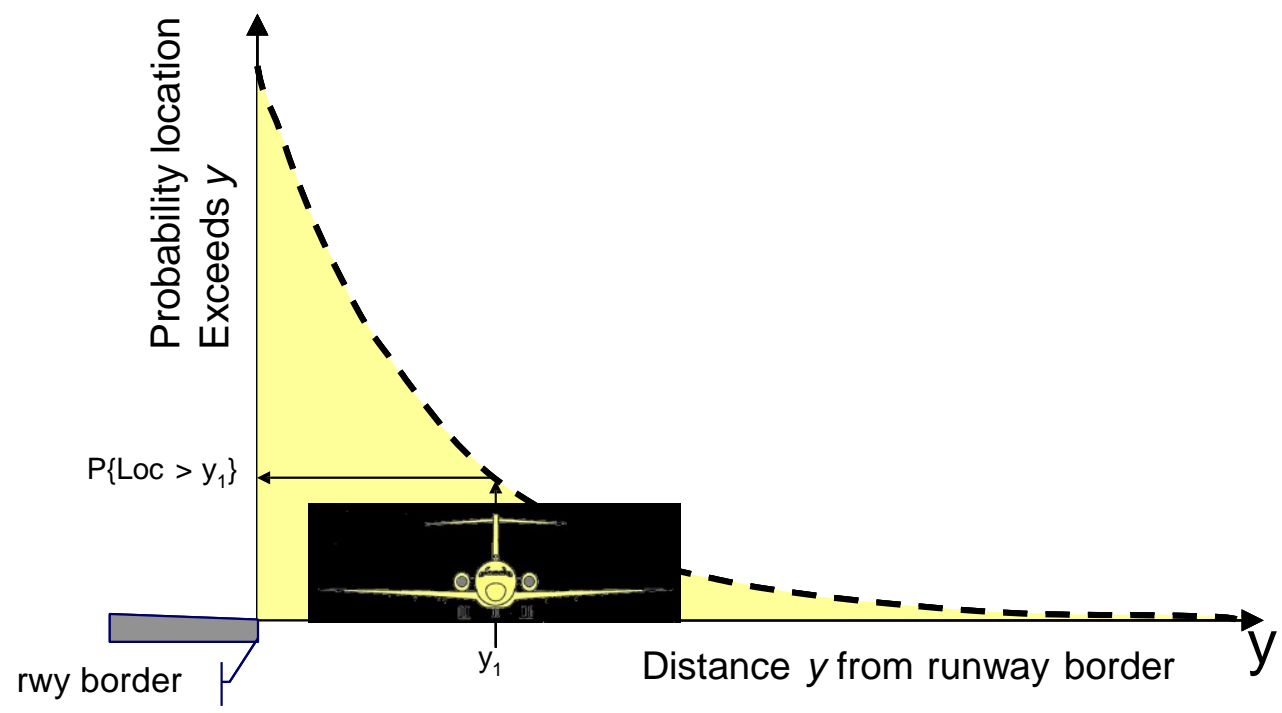

Figure 13. Typical model for aircraft veer-offs 


\begin{tabular}{|l|l|l|l|r|}
\hline $\begin{array}{l}\text { Type of } \\
\text { Accident }\end{array}$ & Coefficients a & Coefficients $n$ & $R^{2}$ & $N$ \\
\hline LDOR & 0.00321 & 0.98494 & 0.998 & 305 \\
\hline LDUS & 0.00148 & 0.75150 & 0.987 & 83 \\
\hline TOOR & 0.00109 & 1.06764 & 0.992 & 89 \\
\hline
\end{tabular}

Table 1a. Location Models, Longitudinal X Models

\begin{tabular}{|l|l|l|r|r|}
\hline $\begin{array}{l}\text { Type of } \\
\text { Accident }\end{array}$ & Coefficients $b$ & Coefficients $m$ & $R^{2}$ & $N$ \\
\hline LDOR & 0.20983 & 0.48620 & 0.939 & 225 \\
\hline LDUS & 0.02159 & 0.77390 & 0.986 & 86 \\
\hline LDVO & 0.02568 & 0.80395 & 0.915 & 126 \\
\hline TOOR & 0.04282 & 0.65957 & 0.987 & 90 \\
\hline TOVO & 0.01639 & 0.86346 & 0.942 & 39 \\
\hline
\end{tabular}

Table 1b. Location Models, Transverse Y Models

Table 1. Summary of location models

The models are illustrated in Figures 14-21.

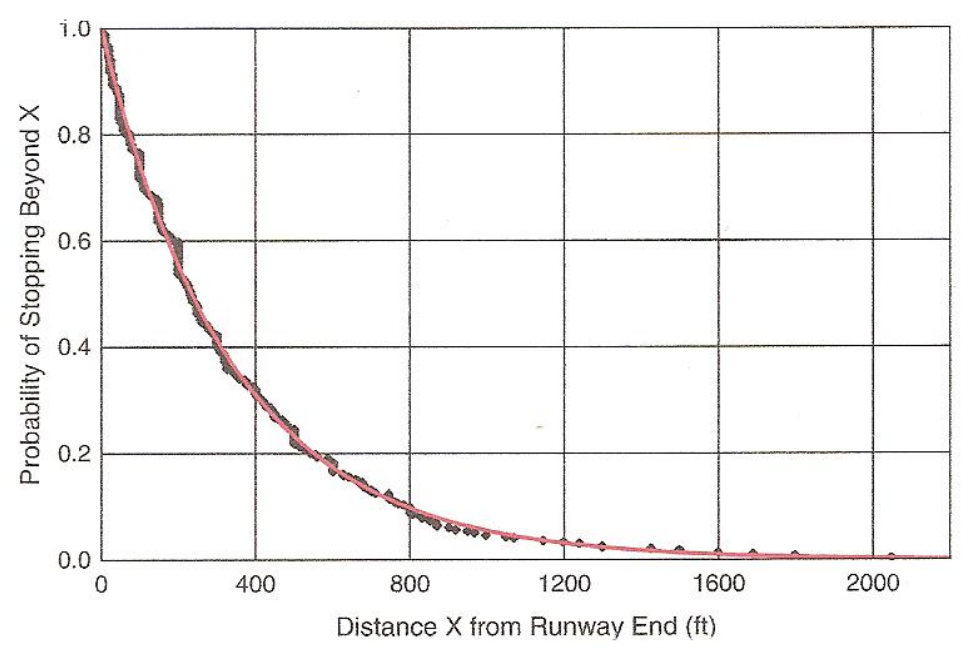

Figure 14: Longitudinal location model for landing overruns 


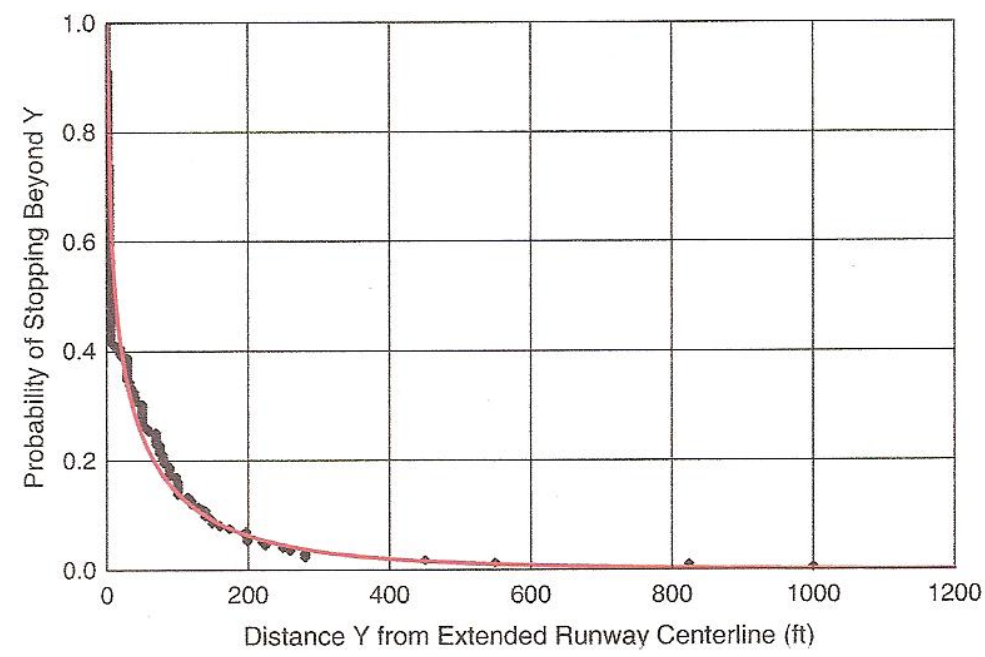

Figure 15: Transverse location model for landing overruns

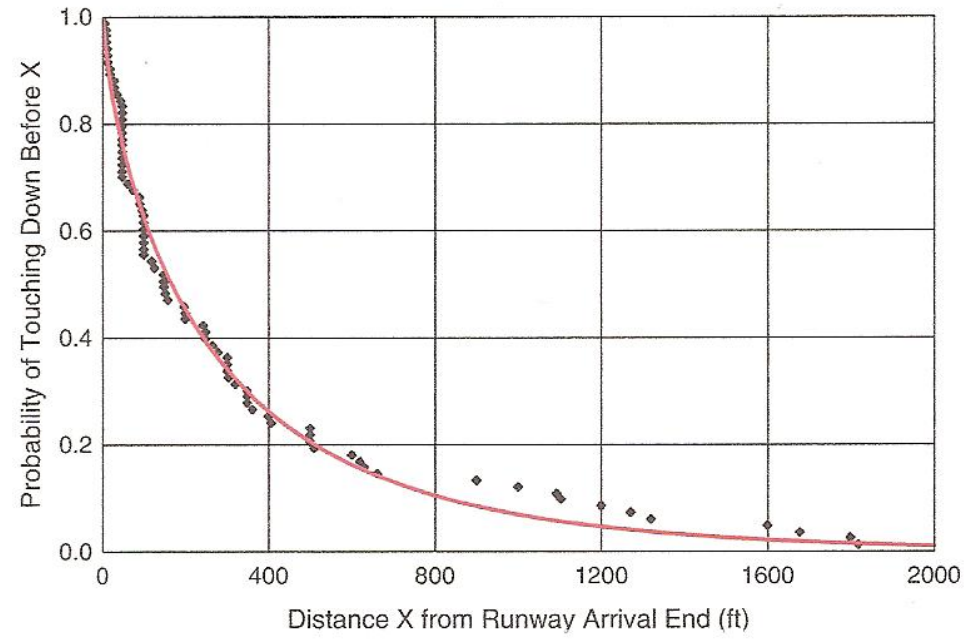

Figure 16: Longitudinal location model for landing undershoots 


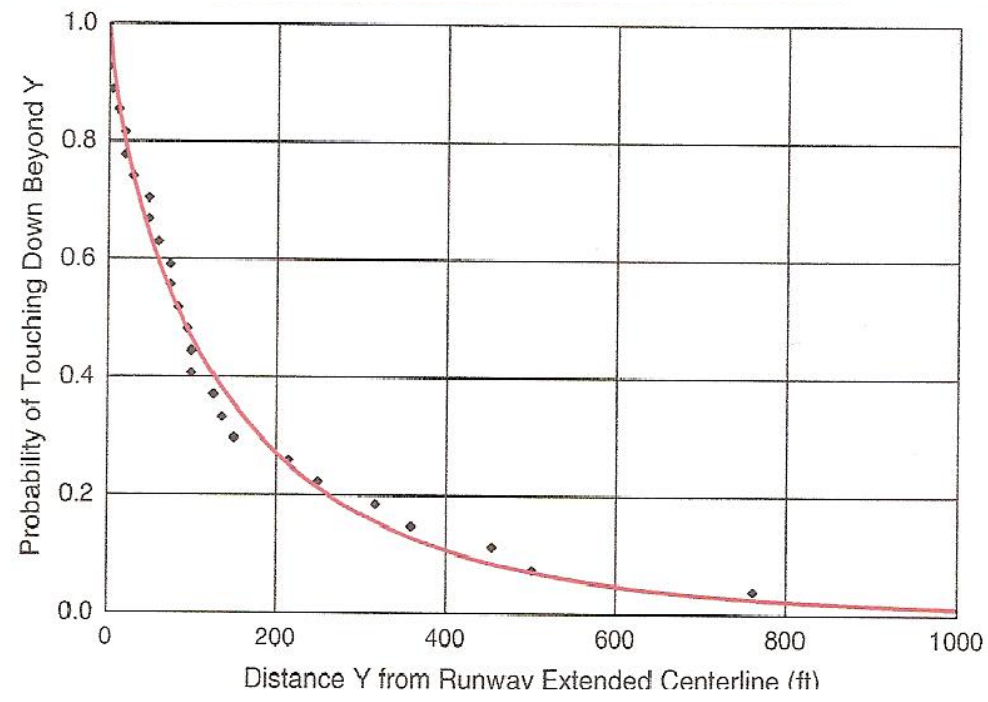

Figure 17: Transverse location model for landing undershoots

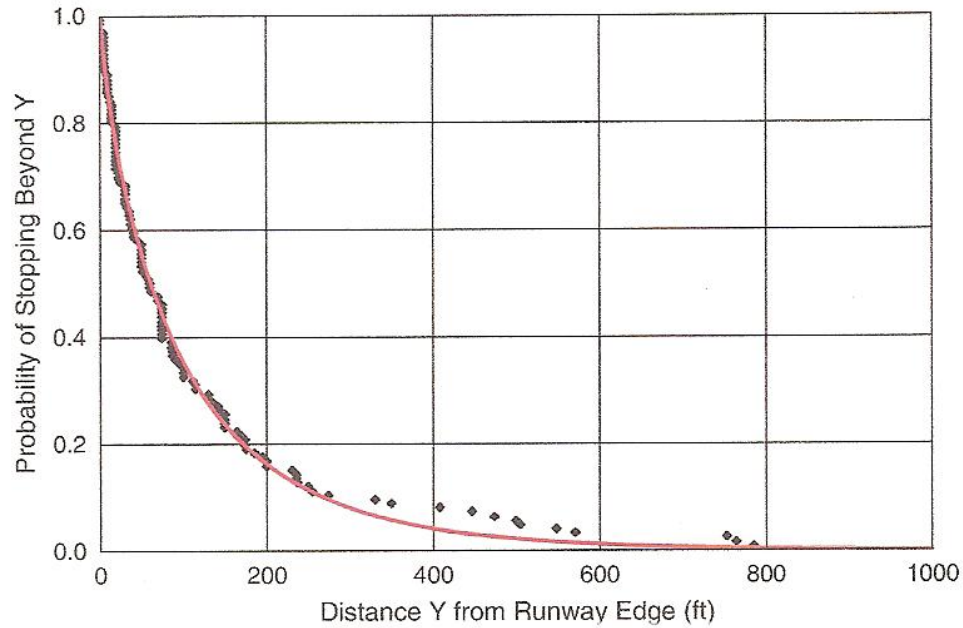

Figure 18. Lateral location model for landing veer-offs 


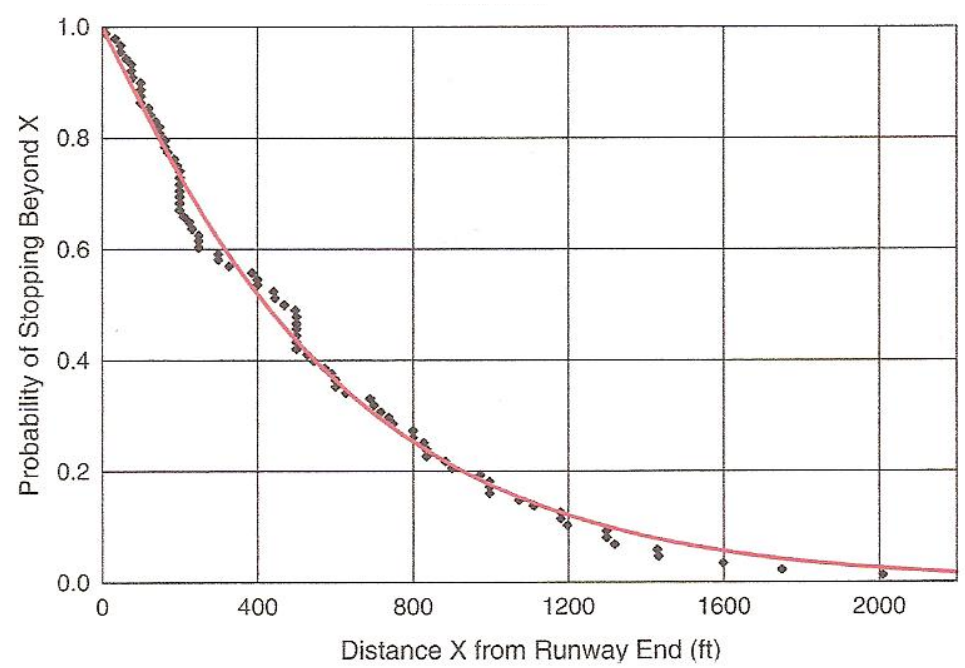

Figure 19. Longitudinal location model for takeoff overruns

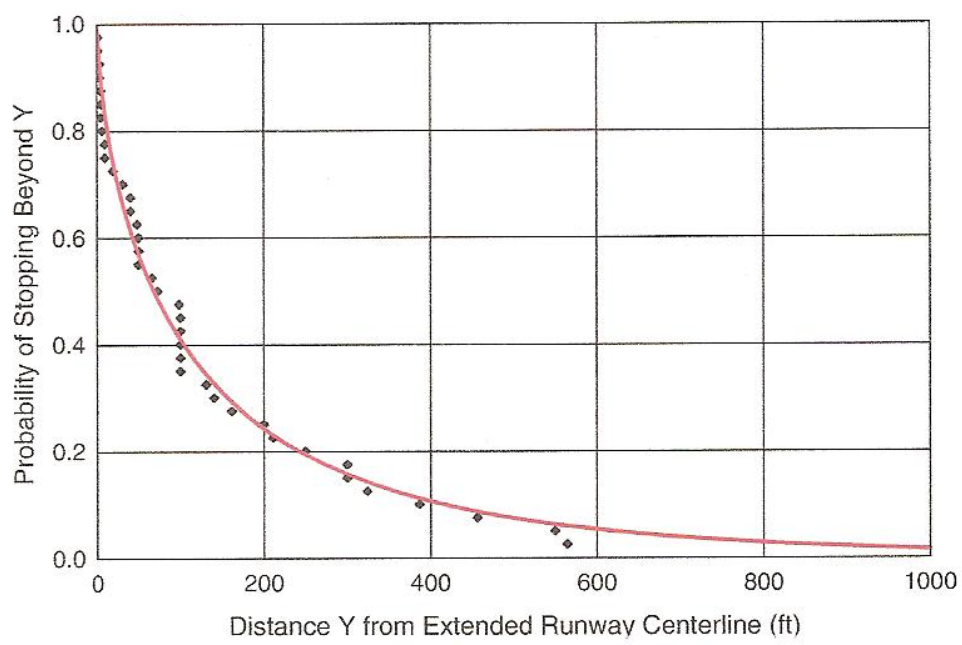

Figure 20. Transverse location model for takeoff overruns 


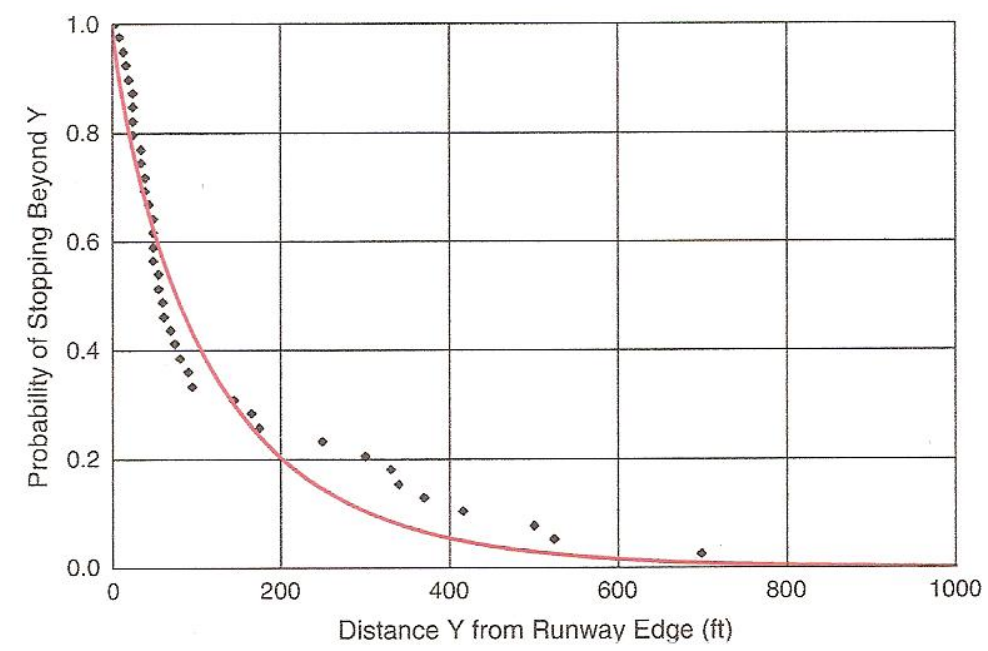

Figure 21. Lateral location model for takeoff veer-offs

Risk is the likelihood of the worst credible consequence for a hazard. Many overruns, veer-offs and undershoots have resulted in aircraft hull loss and multiple fatalities, and therefore, the worst credible level of consequences may be assumed to be catastrophic, according to the severity classification defined by the FAA and presented in Appendix F of ACRP(2011).

In some situations, a pilot may lose control of the aircraft, resulting in the destruction of the equipment with possible fatalities, even when the aircraft accident takes place 
inside the RSA or the runway; however, in the majority of accidents, the RSA will offer some protection to mitigate consequences. Consequences will depend on the type of structures and the level of energy during the aircraft collision. Possible obstacles may include buildings, ditches, highways, fences, pronounced drops in terrain, unprepared rough terrain, trees, and even NAVAID structures, like approach lighting system (ALS) towers and Localiser antennas, particularly if mounted on sturdy structures.

The energy of the aircraft during the collision is related to its speed when it strikes the obstacle, i.e. the greater speeds are expected to result in more severe consequences. Also, the consequences will depend on the type of obstacle. An aircraft striking a brick building at $40 \mathrm{mph}$ may be destroyed whereas if the obstacle is a perimeter fence less severe consequences are expected to occur.

The variables assumed to have an impact on consequences resulting from overruns, veer- offs, and undershoots are:

- $\quad$ Obstacle type, size and location

- $\quad$ Aircraft Size (wingspan) and speed

The basic approach is that presented in ACRP (2008), as summarised in the ensuing sections. The approach described in ACRP (2008) was intended to model accident and incident consequences so that they could be combined with the probability of aircraft overruns and undershoots for an assessment of risk. The approach is rational because it is based on physical and mathematical principles. 
The basic idea was to assess the effect of different obstacles at various locations in the vicinity or inside the RSA. The approach integrates the probability distributions defined by the location models with the location, size, and characteristics of existing obstacles in the runway RSA and its vicinity. The implementation of the approach required some simplifying assumptions so that it could be integrated with the frequency and location models. The following are the assumptions used:

1. Aircraft overrunning, undershooting, or veering off the runway will strike the obstacle in paths parallel to the runway direction. This assumption is necessary to define the area of influence of the obstacle.

2. Four categories of obstacles are defined as a function of the maximum speed that an aircraft may collide with an obstacle, with small chances of causing hull loss and injuries to its occupants:
a. Category 1: Maximum speed is nil (e.g., cliff at the RSA border, concrete wall).
b. Category 2: Maximum speed is 5 knots (e.g., brick buildings).
c. Category 3: Maximum speed is 20 knots (e.g. ditches, fences).
d. Category 4: Maximum speed is 40 knots (e.g., frangible structures, ALS).

3. Severe damage and injuries are expected only if the aircraft collides within the central third of the wingspan and with a speed higher than the maximum for that obstacle category. 
4. The lateral distribution is random and does not depend on the presence of obstacles. This is a conservative assumption because there are events when the pilot will avoid the obstacles given by ILS and Approach Lighting System (ALS) structures in the RSA if he has some directional control of the aircraft.

The main purpose of modelling consequences of aircraft accidents is to obtain an assessment of risk based on the likelihood for the worst credible consequence. It was not deemed necessary to develop a consequence model for each type of accident, as was done to model frequency and location. The approach used can be used to address any of the five types of incidents included in the analysis.

The basic idea is to use the location models to estimate the incident occurrences for which the aircraft will have high energy when striking an obstacle, thus resulting in serious consequences. It should be noted that neither of the models used in the approach provides an estimate of the aircraft speed; however, using the location model and the average aircraft deceleration during a runway excursion, it is possible to infer the probability that the speed is above a certain level when reaching the obstacle. Figure 22 is used to illustrate the case for overruns and help understand 
the principle. This approach was introduced in ACRP Report 3 (2008).

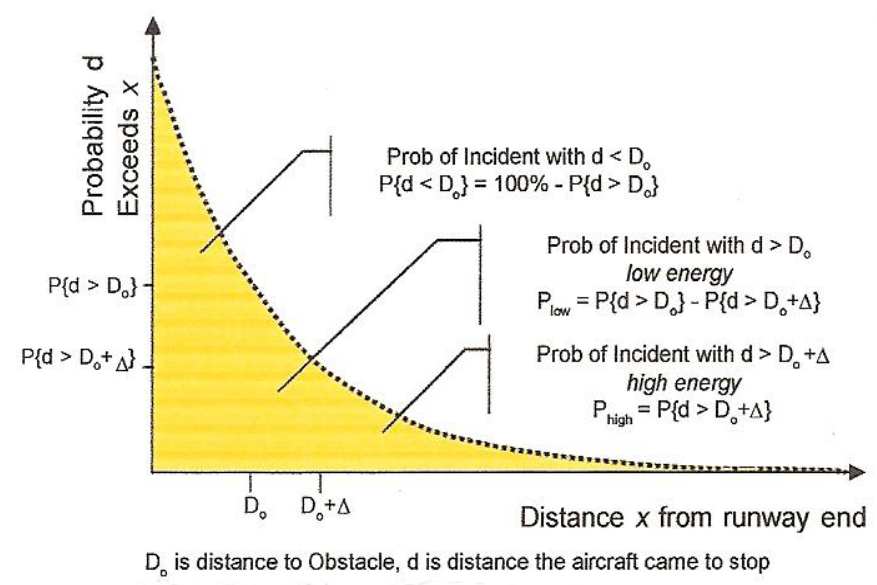

Figure 22. Approach to model consequences of over- run accidents.

The $x$-axis represents the longitudinal location of the wreckage relative to the runway departure end. The $y$-axis is the probability that the wreckage location exceeds a given distance, $x$.

In this example, an obstacle is located at a distance $D_{0}$ from the departure end, and the example scenario being analysed is an aircraft landing overrun incident. Figure 14 shows an exponential decay model developed for the specific accident scenario, in this case, landing overruns.

There are three distinct regions in this plot in Figure 22. The first region represents overruns where the aircraft departed the runway but the exit speed was relatively low and the aircraft came to a stop before reaching the existing obstacle. The consequences for such incidents associated with that specific obstacle are expected to be none if the $x$-location is smaller than $D_{0}$. 
The rest of the curve represents events that the aircraft exited the runway at speeds high enough for the wreckage path to extend beyond the obstacle location. However, a portion of these accidents will have relatively higher energy and should result in more severe consequences, while for some cases the aircraft will be relatively slow when hitting the obstacle so that catastrophic consequences are less likely to happen. Using the location model, if $x$-location is between $D_{0}$ and $D_{0}+\Delta$, it may be assumed that no major consequences are expected if the obstacle is present.

The value of $\Delta$ is ideally estimated based on aircraft deceleration over different types of terrain (paved, unpaved, or EMAS), crashworthiness speed criteria for aircraft type and size and the type of obstacle. Frangible objects in the RSA are less prone to causing severe consequences. It also should be noted that lighter aircraft may stop faster and the landing gear configuration also may have an effect on the aircraft deceleration in soft terrain, but most of these factors are not accounted for in this approach.

Using this approach, it is possible to assign three scenarios: the probability that the aircraft will not hit the obstacle; the probability that the aircraft will hit the obstacle with low speed and energy; and the probability that the aircraft will hit the obstacle with high energy.

For those events with low energy when impacting the obstacle, it is possible to assume that, if no obstacle was present, the aircraft would stop within a distance from the location of the obstacle. The problem is then to evaluate the rate of these accidents having low speeds at the obstacle location, and this is possible based on 
the same location model. This probability can be estimated by excluding the cases when the speed is high and the final wreckage location is significantly beyond the obstacle location.

To complement the approach it is necessary to combine the longitudinal and transverse location distribution with the presence, type, and dimensions of existing obstacles. The basic approach is represented in Figure 23 for a single and simple obstacle.

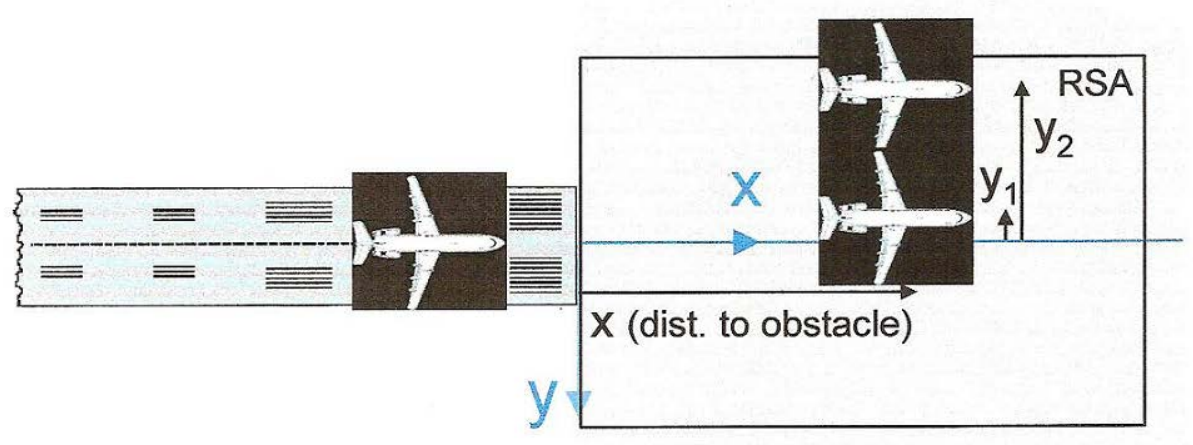

Figure 23. Modelling consequences

Laterally, if part of the obstacle is within the yellow zone, as shown in Figure 24a, medium consequences are expected; however, if any part of the obstacle is within the orange zone, as shown in Figure 24b, and the speed is high, severe consequences are expected. If the obstacle is off the orange and yellow zones, no consequences related to that obstacle are expected. 
a)
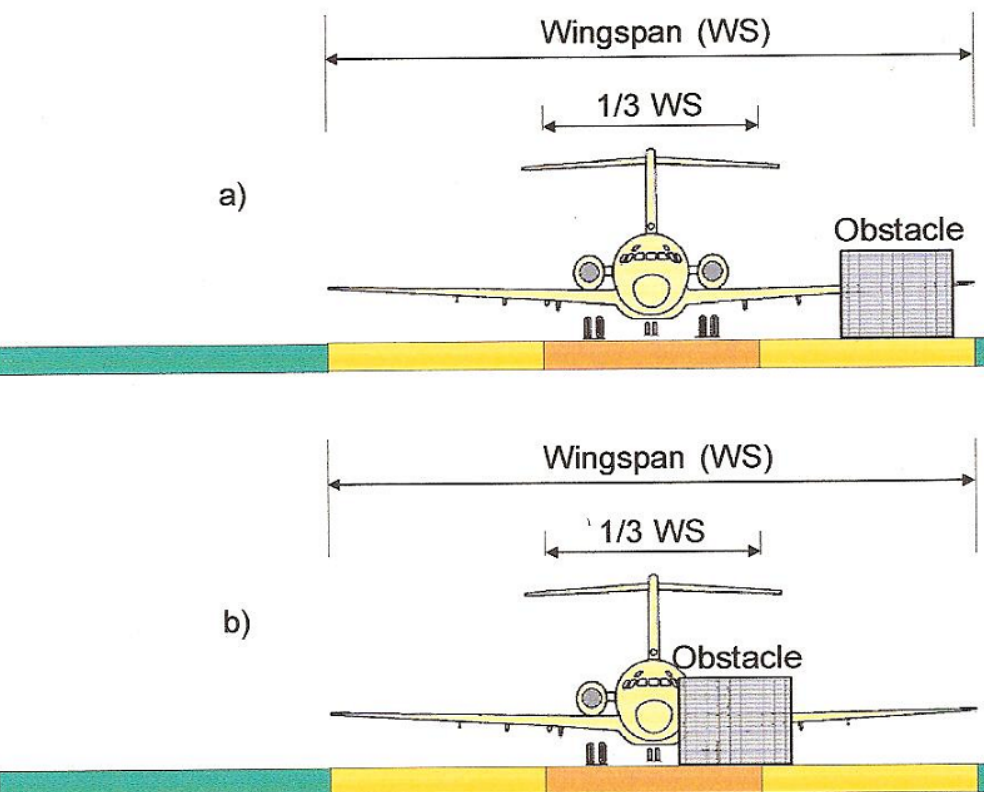

Figure 24. Lateral location versus consequences

In Figure 25, Obstacle 1 is located at a distance $x_{1}, y_{1}$ from the threshold and has dimensions $W_{1} \times L_{1}$. When evaluating the possibility of severe consequences, it is possible to assume this will be the case if the aircraft fuselage or a section of the wing close to the fuselage strikes the obstacle at high speed. Thus, it is possible to assume the accident will have severe consequences if the y location is between $y_{c}$ and $y_{f}$, as shown in the figure. Based on the location models for lateral distance, the probability the aircraft axis is within this range can be calculated as follows:

$$
P_{s c}=\frac{e^{-b y_{c}^{m}}-e^{-b y_{f}^{m}}}{2}
$$

where:

- $\quad P_{s c}$ is the probability of high consequences 
- $\quad b, m$ are regression coefficients for the $y$-location model

- $y_{c}$ is the critical aircraft location, relative to the obstacle, closest to the extended runway axis

- $y_{f}$ is the critical aircraft location, relative to the obstacle, farther from the extended runway axis

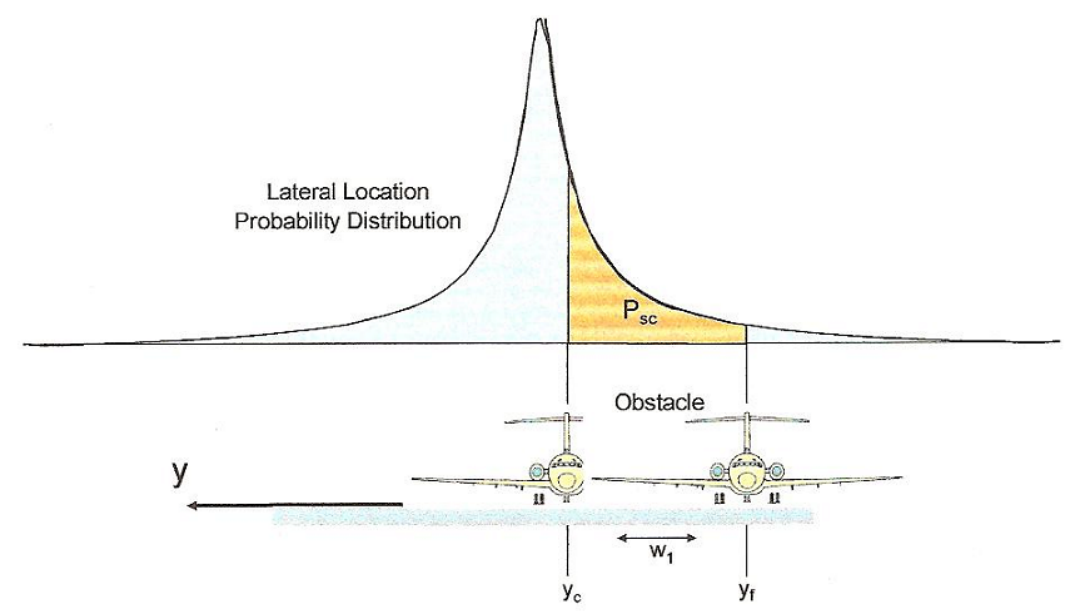

Figure 25. Modelling likelihood of striking an obstacle

Combining this approach with the longitudinal distribution approach and the possibility of multiple obstacles, the risk for accidents with severe consequences can be estimated using the following model:

$$
P_{s c}=\sum_{i=1}^{N} \frac{\left(e^{-b y_{c i}^{m}}-e^{-b y_{f i}^{m}}\right)}{2} e^{-a\left(x_{i}+\Delta_{i}\right)^{n}}
$$

where 
- $\quad N$ is the number of existing obstacles

- $\quad a, n$ are regression coefficients for the $\mathrm{x}$-model

- $\Delta_{i}$ is the location parameter for obstacle $i$

\section{An Example Implementation of Approach}

The implementation of the proposed approach is best explained using an example. Figure 26 depicts an area adjacent to the runway end with two obstacles. The area isn't necessarily the official airport RSA but any available area that can be used by an aircraft overrunning the runway end. The example shows the safety area surrounded by a cliff limiting its boundaries. Obstacle 1 is not frangible and is classified as a Category 2 obstacle (e.g. building), maximum collision speed of 5 knots, located at distance $x_{1}$ from the runway end. For this obstacle, the maximum speed without severe consequences is estimated to be 5 knots. A second obstacle is a small size tree classified as Category 4, maximum speed of 40 knots, and located at distance $x_{2}$ from the runway end. The remaining safety area is defined by the cliff surrounding the RSA and such boundary is classified as Category 1, maximum speed of 0 knots.

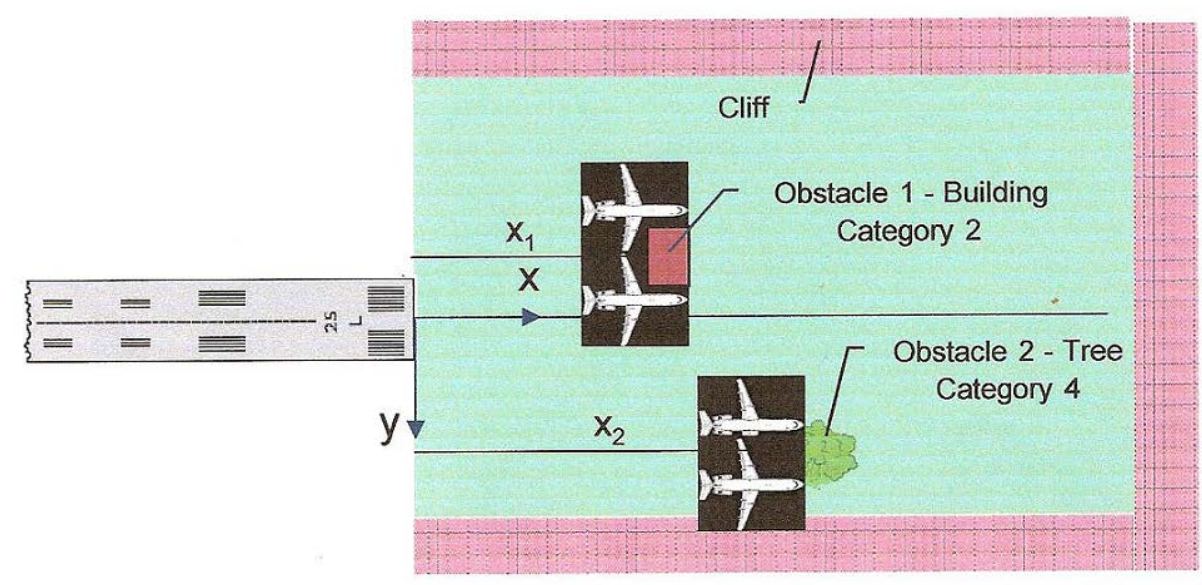

Figure 26. RSA scenario with obstacles 
The typical aircraft deceleration in unpaved surfaces is $0.22 g$, where $g$ is the acceleration due to gravity $\left(32.2 \mathrm{ft} . / \mathrm{s}^{2}\right)$. Using the relationship between acceleration, velocity, and distance, $\Delta$, can be calculated as shown in Table 2 .

Table 2 Obstacle categories

\begin{tabular}{|c|c|c|}
\hline $\begin{array}{c}\text { Obstacle } \\
\text { Category }\end{array}$ & $\begin{array}{c}\text { Max } \\
\text { Speed }\end{array}$ & $\Delta(f t)$ \\
\hline 1 & 0 & 0 \\
\hline 2 & 5 & 20 \\
\hline 3 & 20 & 80 \\
\hline 4 & 40 & 320 \\
\hline
\end{tabular}

The values presented will be used to reduce the safety area so that only the effective portion where the aircraft may stop without severe damage is considered in the analysis. To perform the analysis, the frequency and location models are combined in a manner similar to that for the analysis without obstacles; however, the safety area is transformed to account for the presence of the obstacles, as shown in Figure 27.

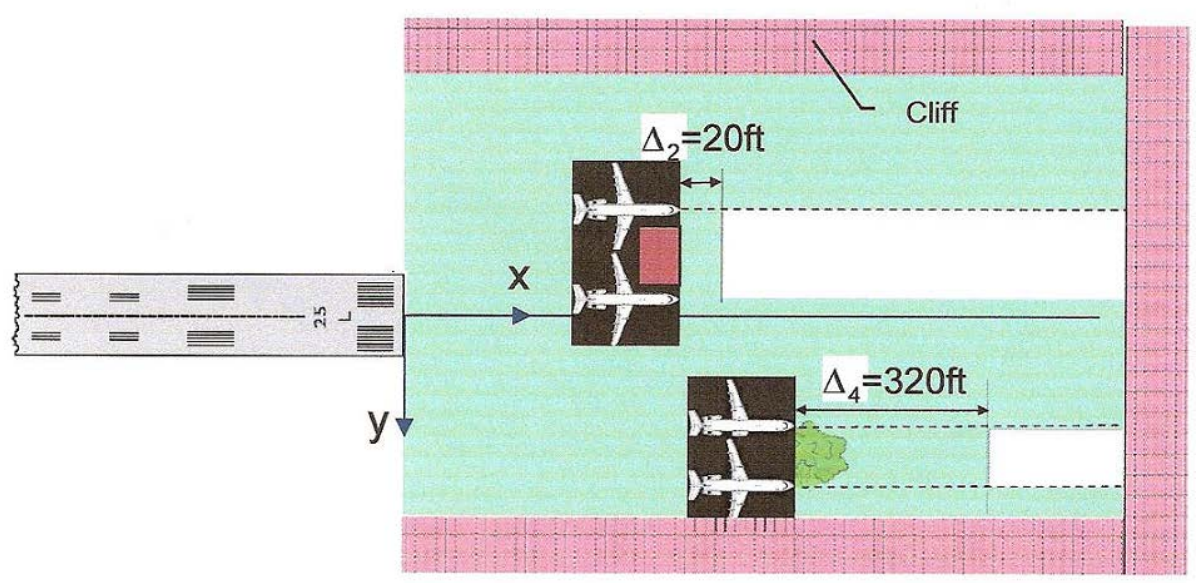

Figure 27. Effective RSA for analysis 
The analysis will provide the probability that the aircraft will overrun the runway and the incident will have severe consequences, thus providing an estimate of risk.

\section{Conclusions}

It has been demonstrated in the work at Loughborough, continued by ACRP, that the framework of modelling aircraft accident frequency, location and consequence has merit. Location models could be improved if greater attention was paid to causality but data difficulties exist, for example, on meteorological influences on distance and that $y$ is often mis-recorded in accident dockets so lateral deviations are more difficult to model. The influence of excess distance (difference between runway length and required distance for the operation) on location should also be accounted for.

Consequence modelling is bound to have particular local elements and is perhaps best dealt with in the ad hoc manner described here. But variation in aircraft type, wingspan and speed ought to be included as well as pavement type variations that will affect deceleration. In addition, previous modelling attempts have isolated the importance of modelling the number of obstacles encountered by one crashing aircraft and suggested the importance of having a predictive model of runway exit speed. Another two areas that deserve attention in accident modelling are accidents that occur over $2000 \mathrm{ft}$. but within 10 miles of the runway and accident impacts on third parties. 
$8 \quad$ References

Airport Cooperative Research Program (ACRP, 2008), _ACRP Report 3 - Analysis of Aircraft Overruns and Undershoots for Runway Safety Areas.

Airport Cooperative Research Program (ACRP, 2011) - ACRP Report 50 Improved Models for Risk Assessment of Runway Safety Areas.

Boeing (2010), Statistical Summary of Commercial Jet Airplane Accidents, Worldwide Operations, 1959 - 2010, July 2010.

David, R., (1990), Location of aircraft accidents/incidents relative to runways. DOT/FAA/AOV90-1. Office of Safety Oversight, Federal Aviation Administration, Washington DC.

Eddowes, M, J. Hancox \& A. Maclnnes, (2001), Final Report on the Risk Analysis in Support of Aerodrome Design Rules, AEAT/RAIR/RD02325/R/002 Issue 1, A Reported Produced for the Norwegian Civil Aviation Authority.

Kirkland,I.D.L., Caves, R.E., Humphreys, I.M. Pitfield, D.E. (2004), An improved methodology for assessing risk in aircraft operations at airports, applied to runway overruns, Safety Science, 42, 891-905. 
Wong D.K.Y, D.E.Pitfield, R.E.Caves and A. J. Appleyard (2006a), The Development of Aircraft Accident Frequency Models in C. Guedes Soares and E. Zio, eds., Safety and Reliability for Managing Risk, (Taylor and Francis, London).

Wong D.K.Y, D.E.Pitfield, R.E.Caves and A. J. Appleyard (2006b), Quantifying and characterising aviation accident risk factors, Journal of Air Transport Management, $12,352-357$.

Wong, D.K.Y., (2007), The Modelling of Accident Frequency Using Risk Exposure Data for the Assessment of Airport Safety Areas, PhD Dissertation, University of Loughborough.

Wong D.K.Y, D.E.Pitfield, R.E.Caves and A. J. Appleyard (2009a), The Development of a more Risk Sensitive and Flexible Airport Safety Area Strategy. Part 1. The development of an improved accident frequency model. Journal of Safety Science, 47, 903-12.

Wong D.K.Y, D.E.Pitfield, R.E.Caves and A. J. Appleyard (2009b), The Development of a more Risk Sensitive and Flexible Airport Safety Area Strategy. Part II. Accident location analysis and airport risk assessment case studies. Journal of Safety Science, $47,913-24$. 